\title{
Mixed connective tissue disease presenting with progressive scleroderma symptoms in a 10-year-old girl
}

\author{
Joanna Latuśkiewicz-Potemska, Agnieszka Zygmunt, Małgorzata Biernacka-Zielińska, Jerzy Stańczyk, \\ Elżbieta Smolewska
}

Department of Pediatric Cardiology and Rheumatology, Clinical Hospital No. 4 of Medical University of Lodz, Poland Head of Department: Prof. Jerzy Stańczyk MD, PhD

Postep Derm Alergol 2013; XXX, 5: 329-336

DOI: 10.5114/pdia.2013.38365

\begin{abstract}
Mixed connective tissue disease (MCTD) is a systemic inflammatory disease affecting connective tissue with the underlying autoimmunological mechanism. The core of MCTD is an appearance of symptoms of several other inflammatory diseases of connective tissue - systemic lupus erythematosus, systemic scleroderma, poly- or dermatomyositis, rheumatoid arthritis at the same time, accompanied by a high level of anti-ribonucleoprotein antibodies (anti-U1RNP). The disease was described more than 40 years ago by Sharp et al. During recent years, many efforts to better understand clinical and serological features of MCTD have been made. Diagnosis of MCTD can be difficult. Obligatory international diagnostic criteria are required to be fulfilled. Several versions of such criteria have been proposed, but the most widely used one was described by Kasukawa. There is no consensus about treatment - a choice of drugs depends on symptoms. We present a case of a 10-year-old girl with sclerodactyly and trophic damages of fingers accompanied by symptoms of Raynaud's phenomenon. After an almost 2-year course of the disease, a diagnosis of MCTD has been established.
\end{abstract}

Key words: mixed connective tissue disease, sclerodactyly, Raynaud's phenomenon, trophic damages of fingers.

\section{Introduction}

Mixed connective tissue disease (MCTD) is a rare connective tissue disease with autoimmune background. Clinically, it is characterized by manifestations that overlap symptoms typical of several other inflammatory diseases of connective tissue - systemic lupus erythematosus, systemic scleroderma, poly- or dermatomyositis, and sometimes rheumatoid arthritis (which is equivalent to juvenile idiopathic arthritis during childhood), while a presence of anti-ribonucleoprotein antibodies (antiU1RNP) in high titer is a typical immunological finding. Mixed connective tissue disease should be distinguished from the overlapping syndromes [1-5].

The incidence of this condition is about 2.7 per 100,000 [1]. During childhood it usually starts between 2 and 16 years of age (mean - 11 years) and it afflicts girls more frequently [2].

Symptoms of MCTD usually develop gradually over a few years. The primary clinical features are Raynaud's phe- nomenon, swollen fingers ("sausage digits") or diffuse swelling of hands, arthralgia with or without arthritis, gastroesophageal reflux or esophageal dysmotility, sclerodactyly, myalgia or inflammatory myopathy. Additional symptoms might include: rashes, alopecia, anemia, leucopenia, lymphadenopathy, secondary Sjogren's syndrome, trigeminal neuralgia as well as mild fever and fatigue [1-5]. Hypergammaglobulinemia, circulating immune complexes, hypocomplementemia and high titer of specific antibodies are the laboratory abnormalities observed in MCTD [1-5]. It usually takes 1.7 years from the time of first symptoms to establish the proper diagnosis [2].

The definition of MCTD is set upon one of the internationally established classification criteria [4, 5]. The criteria of Kasukawa are the most widely used as they are considered to be the most precise [1, 2]. They include: symptoms common to all the diseases involved (Raynaud's phenomenon, swollen fingers), presence of specific antiRNP antibodies and selected symptoms typical of each of the particular component disease separately (systemic

Address for correspondence: Agnieszka Zygmunt MD, PhD, Department of Pediatric Cardiology and Rheumatology, Clinical Hospital No. 4 of Medical University of Lodz, 36/50 Sporna St, 91-738 Lodz, Poland, phone: +48 42617 77 00, e-mail: agnieszka2zygmunt@gmail.com Received: 3.01.2013, accepted: 20.08.2013. 
lupus erythematosus, systemic sclerosis, polymyositis). The disease can be confirmed when there is at least one common symptom, positive antibodies reacting with U1RNP, and at least one symptom from each of the component diseases [1, 2, 4, 5].

During the developmental period the course of the disease is milder in comparison to adults [2, 3]. In the majority of patients, after a few years the activity of the disease is low [1-3]. Choice of the therapy, as well as prognosis, depends on the type of organ involvement. The most frequent causes of death are connected with development of pulmonary hypertension and interstitial lung disease [1-5]. The treatment is determined based on the kind of the involved organ and intensity of the disease activity. Usually patients react to low doses of steroids, non-steroidal anti-inflammatory drugs, in combination with immunosuppressive drugs or biologic agents in the form of monoclonal antibodies $[1,2,4,5]$.

\section{Case report}

A 10-year-old girl was admitted to the Department of Pediatric Cardiology and Rheumatology with a suspicion of localized scleroderma. The patient reported hardening and tightening of the skin of fingertips of both hands, which had started about 1.5 years earlier. It had been occasionally accom- panied by minor trophic changes in the region of the nail folds. Moreover, the patient had complained of episodes of chilling and cyanosis of fingers, especially after exposure to cold, as well as during emotional distress. Because of those symptoms the child had been a patient of the Dermatology Outpatient Clinic, and later on, due to inefficiency of the treatment, she had been referred to the Department of Pediatric Dermatology in order to perform further diagnostic workup. A series of laboratory tests had been performed at that time, which had shown low indices of the inflammatory process and normal hematological and biochemical parameters (Table 1). A parasitic infection had been excluded, and so had allergic reaction (concentration of both total and allergen-specific IgE had been within normal range). The VDRL test had been negative. However, the patient had been positive for the rheumatoid factor and antinuclear antibodies with a diffuse and speckled pattern of immunofluorescence and a titer of $1: 1280$, specific anti-Ro (++) and anti-RNP/Sm $(+++)$ antibodies were also present (Table 2$)$. The lupus erythematosus (LE) cells had not been found.

At that time a tentative diagnosis of an early stage of limited systemic scleroderma had been established. Treatment with procaine penicillin, pentoxifylline and tocopherol had been initiated, and topical treatment had been carried out at the same time.

Table 1. Values of selected hematological and biochemical parameters

\begin{tabular}{|c|c|c|c|c|c|c|}
\hline Laboratory test & 26.11.2009 & 15.02 .2010 & 15.06 .2010 & 4.02 .2011 & 14.07 .2011 & $7.10 .2011^{*}$ \\
\hline $\mathrm{ESR}[\mathrm{mm} / \mathrm{h}]$ & 4 & - & 4 & 12 & 13 & 7 \\
\hline CRP $[\mathrm{mg} / \mathrm{dl}]$ & 0.1 & & 0.61 & 0.01 & 3.3 & 0.2 \\
\hline $\mathrm{HGB}[\mathrm{g} / \mathrm{dl}]$ & 13 & 13.1 & 12.3 & 13.4 & 12.4 & 14.1 \\
\hline $\operatorname{RBC}\left[10^{6} / \mu \mathrm{l}\right]$ & 4.64 & 4.44 & 4.37 & 4.54 & 4.35 & 4.85 \\
\hline MCHC [g/dl] & 32.9 & 34.4 & 33.4 & 34.2 & 33.6 & 33.0 \\
\hline WBC $\left[10^{3} / \mu \mathrm{l}\right]$ & 8.9 & 7.9 & 7.1 & 6.2 & 7.5 & 8.9 \\
\hline $\operatorname{PLT}\left[10^{3} / \mu \mathrm{l}\right]$ & 410.0 & 354.0 & 402.0 & 363.0 & 347.0 & 460.0 \\
\hline ALAT [U/I] & 10 & 8 & 8 & 14 & 9 & 8 \\
\hline ASPAT [U/I] & 18 & 17 & 14 & 19 & 17 & 15 \\
\hline $\mathrm{LDH}[\mathrm{U} / \mathrm{I}]$ & - & - & - & - & 210 & 181 \\
\hline CPK [U/I] & - & - & - & - & 68 & 73 \\
\hline Urea [mg/dl] & 28 & 18 & - & 20.8 & 15.9 & 24.1 \\
\hline Creatinine [mg/dl] & 0.49 & 0.46 & - & 0.40 & 0.43 & 0.52 \\
\hline Urinalysis & Normal & Normal & Normal & Normal & Normal & Normal \\
\hline APTT [s] & - & - & - & - & - & 28.2 \\
\hline INR & - & - & - & - & - & 1.0 \\
\hline Fibrinogen $[\mathrm{mg} / \mathrm{dl}]$ & - & - & - & - & - & 259.414 \\
\hline D-dimers [ $\mu \mathrm{g} / \mathrm{ml}]$ & - & - & - & - & - & 0.16 \\
\hline
\end{tabular}


Table 2. Summary of the relevant immunological test

\begin{tabular}{|c|c|c|c|c|c|c|}
\hline Laboratory test & 26.11.2009 & 15.02 .2010 & 15.06 .2010 & 4.02 .2011 & 14.07.2011 & $7.10 .2011^{*}$ \\
\hline $\operatorname{RF}[I U / m l]$, norm: $<14$ & 19 & - & 18 & 19.7 & - & 15 \\
\hline ANA - titer & $1: 1280$ & $1: 640$ & $1: 320$ & $1: 320$ & $1: 1000$ & $1: 320$ \\
\hline $\begin{array}{l}\text { ANA - pattern of } \\
\text { immunofluorescence }\end{array}$ & $\begin{array}{l}\text { Diffuse and } \\
\text { speckled }\end{array}$ & $\begin{array}{l}\text { Diffuse and } \\
\text { speckled }\end{array}$ & $\begin{array}{l}\text { Diffuse and } \\
\text { speckled }\end{array}$ & Speckled & Speckled & Speckled \\
\hline ENA & $\begin{array}{c}\text { RNP/Sm } \\
(+++) \\
\text { Ro-52 } \\
(++)\end{array}$ & - & - & $\begin{array}{c}\text { nRNp/Sm } \\
\text { (positive) } \\
\text { Ro-52 } \\
\text { (positive) } \\
\text { Sm (positive) }\end{array}$ & $\begin{array}{l}\text { nRNp/S } \\
\text { (positive } \\
\text { Ro-52 ) } \\
\text { (positive) }\end{array}$ & $\begin{array}{c}\text { nRNp/Sm } \\
\text { (positive) } \\
\text { Ro-52 } \\
\text { (positive) } \\
\text { PCNA (doubtful) }\end{array}$ \\
\hline $\begin{array}{l}\text { PANCA } \\
\text { CANCA }\end{array}$ & - & - & - & - & - & $\begin{array}{l}\text { Negative } \\
\text { Negative }\end{array}$ \\
\hline $\begin{array}{l}\text { Anticardiolipin } \\
\text { antibodies }\end{array}$ & - & - & - & - & - & $\begin{array}{l}\text { IgM negative } \\
\text { IgG negative }\end{array}$ \\
\hline$\beta_{2}$-Glycoproteinantibodies & - & - & - & - & - & $\begin{array}{l}\text { IgM negative } \\
\text { IgG negative }\end{array}$ \\
\hline Lupus anticoagulant & - & - & - & - & - & Absent \\
\hline LE cells & Absent & - & - & - & - & - \\
\hline
\end{tabular}

${ }^{*}$ Exacerbation of the disease - pain and oedema of the $3^{\text {rd }}$ fingertip of the left hand, necrotic change with ulceration of this region

After the implemented treatment, a gradual decrease in the ANA titer had been observed (Table 2), however it had not been accompanied with clinical improvement and in the further course of the disease a deterioration of skin changes had been noted. After a year, the patient had been referred to the Department of Pediatric Cardiology and Rheumatology in order to continue the treatment.

On admission, the girl was in quite good general condition. She complained of pain and hyperesthesia of fingertips, as well as skin cracks of these regions and episodes of Raynaud's phenomenon. On physical examination, hardening and tightening of fingertips' skin, "too tight" skin of the palms, small scars on fingertips of the $2^{\text {nd }}$ and $3^{\text {rd }}$ finger of both hands were observed, as well as minor erythematous-desquamative rash over the extension surface of interphalangeal joints.

A broad laboratory and imaging diagnostic work-up was conducted. Routine laboratory tests were within normal ranges (Table 1). A positive rheumatoid factor and antinuclear antibodies with a speckled pattern of immunofluorescence and a titer of $1: 320$ were confirmed, with the presence of specific anti-Ro, anti-RNP and anti-Sm antibodies (Table 2). Anticardiolipin antibodies were not found. Both laboratory and imaging tests assessing the function of internal organs, like chest $X$-ray, barium swallow X-ray, abdominal ultrasound, ophthalmological examination, did not show any abnormalities. The $X$-ray of hands and wrists, apart from poor bone mineralization and slightly accelerated bone age, was insignificant. Thermographic evaluation with a positive result of the cold water immer- sion test, confirmed impaired blood circulation within both hands (Figure 1).

Nailfold capillaroscopy revealed microangiopathy typical of scleroderma (decreased number of vessels, widening or deformation of the remaining ones), with features of vasculitis (Figure 2).

Based on the hitherto clinical course of the disease and results of the diagnostic tests, previous diagnosis was verified and eventually a mixed connective tissue disease was diagnosed, currently with predominant scleroderma symptoms. Because of this, the patient's treatment was modified - she was prescribed hydroxychloroquine in a dose of $200 \mathrm{mg}$ a day and a low dose of prednisone ( $5 \mathrm{mg} /$ day). The girl was advised to avoid exposure to cold in order not to provoke vasospastic reaction, as well as to avoid infections (among others she was started to be taught individually at home). At the follow-up visit after 5 months, she was found to be in quite good condition, with persistent scleroderma symptoms, but without their exacerbation. A new symptom was, however, spotted - erythema of the palms and soles accompanied by epidermal exfoliation. The girl complained also of itching of the affected areas, the skin changes had not been preceded by fever, infection or rash. Laboratory tests revealed an increase in ANA titer up to $1: 1000$ (Table 2) but without progression of microangiopathic changes in control nailfold capillaroscopy of fingers. It was decided to continue the hitherto treatment as new symptoms did not seem to justify any modifications. Itching skin lesions gradually disappeared. 

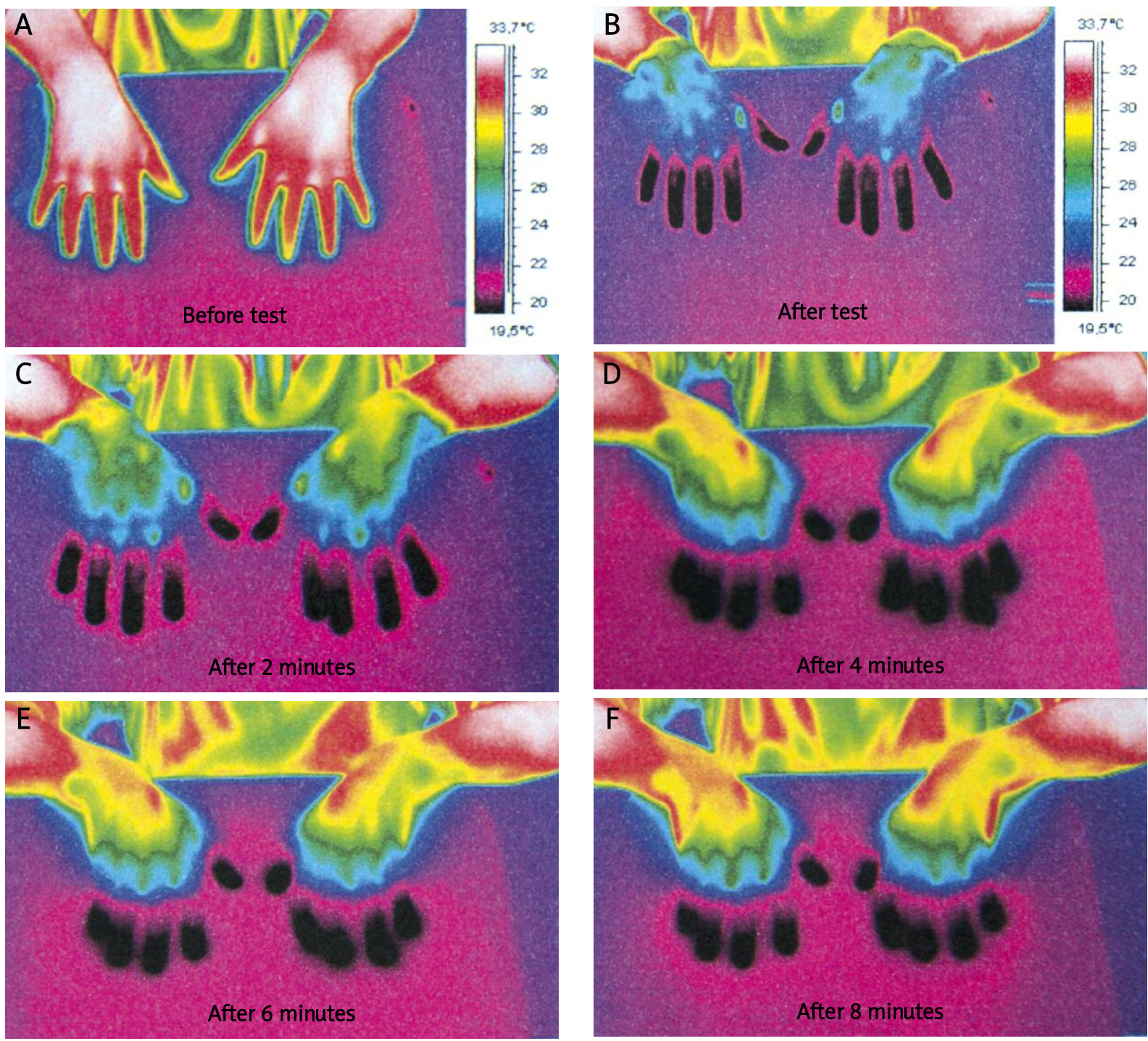

Figure 1. Infrared thermographic test. The positive result of the cold water immersion test. During the test fingers are cooler than metacarpals and wrists. Temperature of both hands does not return to the initial temperature

However, after next 3 months, the child required urgent hospitalization because of exacerbation of her symptoms during the respiratory tract infection. Pain and swelling of the $3^{\text {rd }}$ fingertip of the right hand appeared, followed by necrosis with ulceration (Figure 3). Laboratory tests, including coagulogram, were normal (Table 1). Neither ANCA nor antiphospholipid antibodies were found (Table 2). X-ray of the hands did not reveal any osteitis or osteolysis, only minor calcifications in some of the phalanges. Chest $\mathrm{X}$-ray confirmed the inflammatory process in the lungs. Antibiotic treatment was implemented (first with clindamycin, followed by spiramycin), as well as intravenous pentoxifylline and subcutaneous low-molecularweight heparin. The prednisone dose was increased to $15 \mathrm{mg}$ per day and therapy with hydroxychloroquine was continued. Topical anti-inflammatory treatment was initiated (neomycin, Triderm), together with enzymatic demarcation of necrotic tissues (Iruxol, Manuka honey). At the same time, local thromboprophylaxis of the unaffected toes was conducted (Lioton).

A systematic improvement of the clinical condition was achieved - symptoms of the respiratory tract infection disappeared and necrotic change on the fingertip was gradually healing. The girl was discharged from the hospital in good general condition, with a recommendation of further steroid therapy (prednisone reduced to $10 \mathrm{mg} /$ day) and ambulatory heparin treatment for the next several weeks. At the next follow-up visit in the Rheumatology Outpatient Clinic, the ulceration continued to heal. A small thimblelike scar at the top of the affected fingertip was observed. 

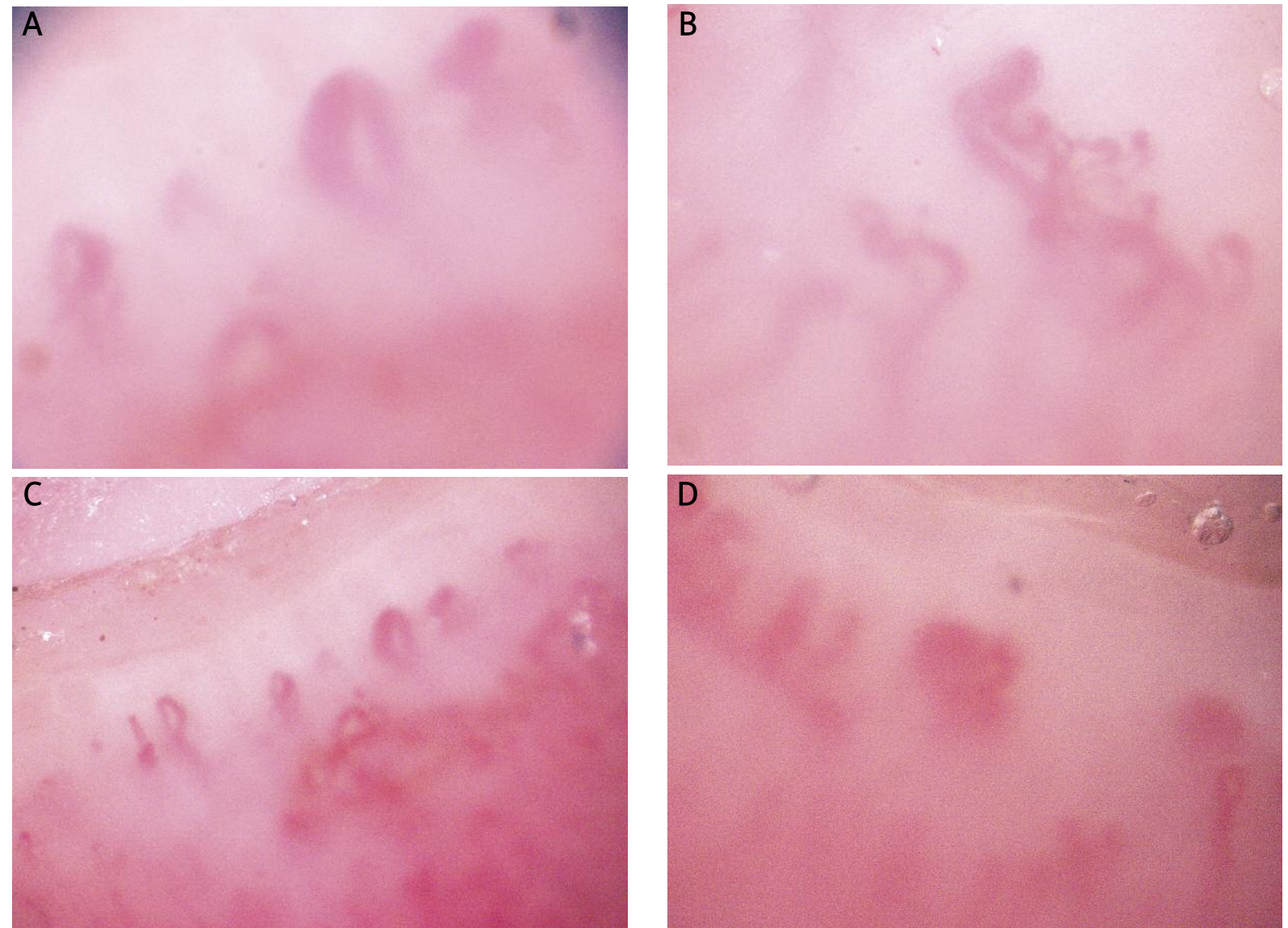

Figure 2. Capillaroscopy pictures. Nailfold capillaroscopy of both hands (magnification 200x). Microangiopathy typical of systemic scleroderma with features of vasculitis. A - Single megacapillary surrounded by slightly dilated loops. B - Vascular loop with multiple branching and spiral-tortuous course, with features of neovascularization. $\mathbf{C}$ - Single megacapillary, next to several dilated loops. Visible avascular areas. D - Irregular loops, visible avascular areas. Two megacapillaries. Small clusters of hemosiderin (old petechiae)

However, skin changes located over the extension surface of interphalangeal joints were more intense and they change into small erythematous scars with epidermal hypertrophy (Gottron's papules characteristic of dermatomyositis). Heparin treatment was stopped after 2.5 months and it was substituted with acetylsalicylic acid in an antiagregant dose. The rest of medications remained unchanged. Later on, as clinical remission maintained and side effects of steroid therapy appeared (face and trunk obesity, increased hunger, heartburn) the daily dose of prednisone was reduced to $5 \mathrm{mg}$.

At present, the girl is asymptomatic. On physical examination, she presents with Cushing-like physique. After a period of some improvement, the skin of fingers is again tighter and harder, the patient is unable to clench fists. Small thimble-like scars are present on the fingertips (the scar on the left $3^{\text {rd }}$ finger is bigger and deeper), as well as Gottron's papules.

A progressive atrophy of the fingertips and episodes of nails blanching, depending on hands and fingers posi-

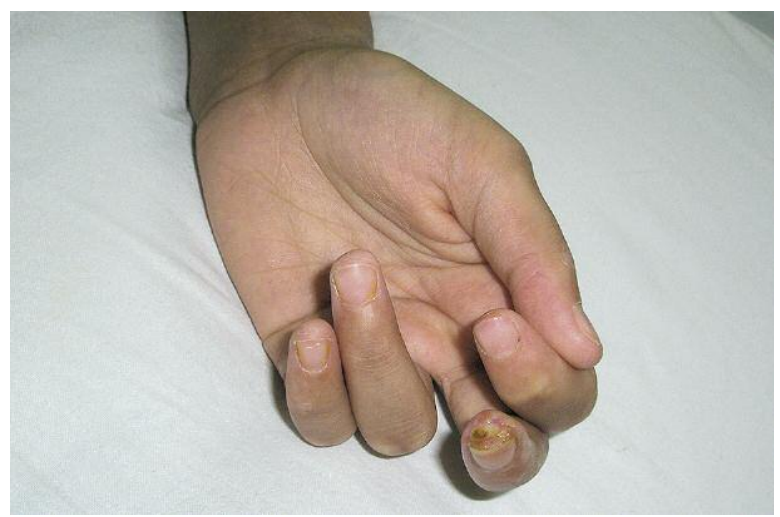

Figure 3. Necrotic change with ulceration on the $3^{\text {rd }}$ fingertip of the left hand

tion, are observed (Figure 4). The girl remains under constant specialist care, and reports regularly on the followup visits. 

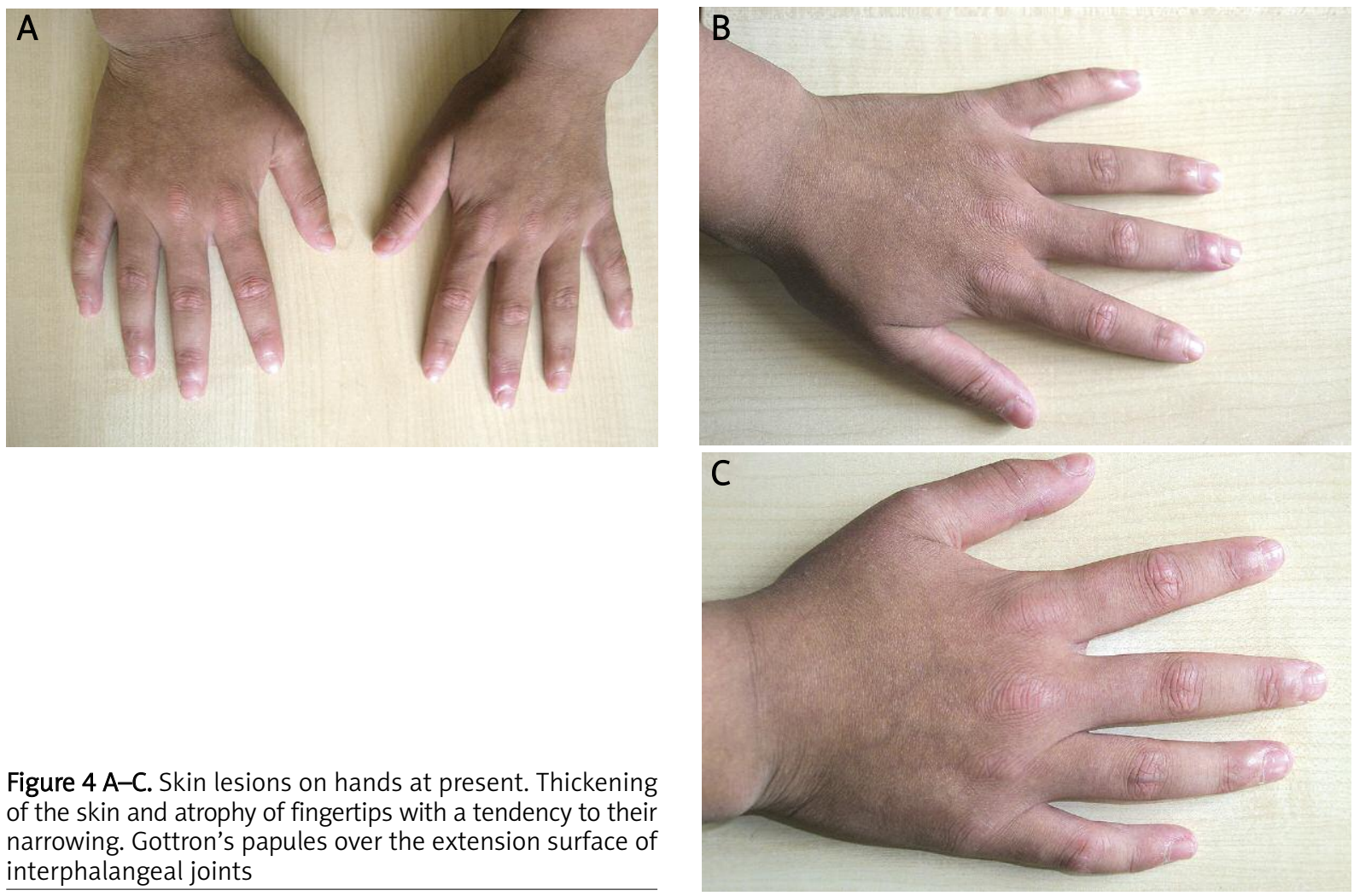

Figure 4 A-C. Skin lesions on hands at present. Thickening of the skin and atrophy of fingertips with a tendency to their narrowing. Gottron's papules over the extension surface of interphalangeal joints

\section{Discussion}

Hardening and tightening of the skin of fingers, especially fingertips, with a tendency to skin cracking of those regions independently of trauma or other external factors, were the first symptoms that prompted the patient to seek medical advice. At that time she also complained of episodes of chilling and cyanosis of hands, especially after exposure to cold, as well as during emotional distress.

Diseases with "hard skin" include systemic scleroderma (SS) and a series of scleroderma-like disorders [6, 7]. They differ in etiology, pathogenesis, clinical course and prognosis. Medsger has divided these conditions into three categories - diseases with primary skin changes, primary systemic diseases which present with skin hardening and diseases caused by genetic or environmental factors (e.g. chemical) leading to skin hardening [6]. The physical examination, clinical course and results of diagnostic tests excluded the diagnosis of rare and very rare disorders from the first [6-10] and third group [6]. Therefore, excessive skin fibrosis in the course of connective tissue diseases, including SS, should be considered [10-13]. This entity can occur alone or as a component of the overlapping syndrome [5] or mixed connective tissue disease. Based on the clinical picture (sclerodactyly, Raynaud's phenomenon) as well as on the results of immunological tests (presence of ANA in high titer $1: 1280$ and speckled pattern of immunofluorescence and specific anti-Ro (++) and anti-RNP/Sm (+++)

antibodies), the patient was initially suspected of limited systemic scleroderma. However, further course of the disease and results of laboratory tests made us verify the diagnosis and finally, based on classification criteria, mixed connective tissue disease was diagnosed.

Golding [14] maintains that skin is involved in all cases of MCTD which are initially diagnosed as systemic lupus erythematosus, systemic sclerosis or dermatomyositis and that the first symptoms include Raynaud's phenomenon and swelling of the hands. The first symptom was present in our patient at the very beginning of the disease.

Moreover, Golding describes a unique case of MCTD in an 18-year-old girl, in whom skin involvement presented as morphea without any other dermatological or systemic symptoms of SS [14].

The disease duration before the correct diagnosis is established and proper treatment introduced are other issues discussed in the literature. Swart and Wulffraat [2] noticed that on average it took 1.7 years from the first symptoms to finally establish the diagnosis of MCTD. They also found that at the early stage of the disease, SS is diagnosed only in $0-3 \%$ of pediatric patients because at that time symptoms of myositis or systemic lupus erythematosus predominate in children.

It is thought that in the developmental period MCTD has a milder course than in adult patients, and that the disease activity gradually decreases and after a few years it becomes low. 
Rummler et al. [15] report that in $70 \%$ of the children, MCTD has a mild course, however in some cases serious complications like: ischemic pain, loss of digits, recurrent infections, changes in the alimentary tract, neuropathy, nephropathy, diseases of brain vessels with intracerebral hemorrhage and pulmonary hypertension (connected with increased mortality) can occur.

The literature also presents descriptions of cases in which the intensity of the inflammatory process is constantly high and within several years of the disease, successive severe complications occur.

Palmer et al. [16] described a 25-year-old woman, who was diagnosed with MCTD at the age of 9 , with a severe course of the disease and a fatal outcome. The patient presented with an intractable ischemic and neuropathic pain in her limbs. Control of such pain is a therapeutic challenge, as resistance to opioid therapy is frequent, even with high parenteral doses, and it might require epidural analgesia. The patient described by the authors had been hospitalized multiple times because of multifocal pain and infected digits, she developed progressive gastrointestinal dysmotility, labile systemic hypertension, pulmonary hypertension complicated by the right heart failure. Apart from intense pharmacological treatment she required to undergo invasive procedures including sympathetic blockade, finger amputations and epidural analgesia.

The girl described in our paper had no clinical symptoms of muscle damage and her muscle enzymes activity was normal. It is generally thought that muscle involvement in MCTD is subclinical and usually presents as elevated levels of muscle enzymes; severe muscle weakness is not observed in this disease. Bonin et al. [17] described a unique case of an adult female patient, in whom initial presentation of MCTD included myositis, characterized by dysphagia, progressive myopathy and muscle weakness, mostly concerning the neck and also shoulder and pelvic girdle. While there was no response to the administration of an initial dose of corticosteroids, improvement was observed after implementation of pulse therapy with methylprednisolone accompanied by methotrexate.

Essalah et al. [18] described an 18-year-old girl with a 13year history of MCTD with a morbid course, who developed glomerulonephritis similar to lupus nephritis with subsequent renal insufficiency and scleroderma-like gastrointestinal disease with crampy abdominal pains, vomiting, diarrhea, considerable weight loss and hepatocellular dysfunction. Since there is no effective pharmacological treatment for this presentation of MCTD, authors state that the only hope for such severe organ involvement might be multi-organ transplantation.

The patient described in our paper had no evidence of internal organ involvement so far. She did not complain of limb pains, either. During a period of decreased immunity in the course of the respiratory tract infection, she presented, however, with a fairly extensive ulceration of the fingertip skin. Thanks to prompt hospitalization and therapy modification, digit amputation could be avoided.
No uniformly effective therapy is available for MCTD. The treatment is organ-specific and depends on the kind of internal organ involvement, the phase of the disease and the rate of its progression. There are no medications that would effectively stop progression of the disease [10-12]. Treatment is aimed at controlling the main pathogenetic mechanisms: vasculopathy which leads to tissue ischemia, immunological and inflammatory processes deriving from autoimmunity and excessive fibrosis caused by redundant synthesis of collagen and other matrix proteins [10, 12, 13]. In most cases, MCTD can be effectively treated by systemic steroids and immunosuppressive drugs: methotrexate, cyclosporine, mycophenolate mofetil, azathioprine and chloroquine. However, not all patients respond to such therapy. Immunoglobulins, cytotoxic agents like cyclophosphamide or biologic drugs can be administered in refractory cases or in severe clinical conditions. Plasmapheresis might also be a therapeutic option, especially when it is combined with agents that can block production of pathogenic autoantibodies, like rituximab which is a monoclonal antibody anti-CD20 and modulates the disease activity [19].

Rummler et al. [15] described a 11-year-old boy with MCTD and life-threatening pulmonary hypertension (which is considered the most severe complication with high mortality) and progressive heart failure, showing no improvement after intensive immunosuppressive therapy and high-dose steroids, who responded to 22 sessions of extracorporeal, selective immunoadsorption onto protein A. The patient was not given rituximab because parents did not consent.

Summarizing, it should be emphasized that different forms of connective tissue diseases, especially at early phases, may be very difficult to define. Because of this it may take several months or years to establish the final diagnosis. Besides, in some cases diagnosis must be made based on clinical and serological manifestation, as definite classification criteria for a specific disease are not fulfilled. Childhood MCTD may be a diagnostic challenge at the early stage. However, with a long-term course the disease becomes usually milder and the activity of inflammatory process tends to gradually decrease.

\section{Acknowledgments}

Authors of the paper would like to thank to Professor Anna Gorska for sharing the pictures documenting changes in microvasculature of the patients during the initial nailfold capillaroscopy as well as for her valuable comments.

\section{References}

1. Puszczewicz M. Mieszana choroba tkanki łącznej. In: Wielka Interna. Reumatologia [Polish]. Puszczewicz M (ed.). Medical Tribune Polska, Warsaw 2010; 157-62.

2. Swart JF, Wulffraat NM. Diagnostic workup for mixed connective tissue disease in childhood. Isr Med Assoc J 2008; 10: 650-2. 
3. Hoffman RW, Maldonado ME. Immune pathogenesis of mixed connective tissue disease: a short analytical review. Clin Immunol 2008; 128: 8-17.

4. Ortega-Hernandez OD, Shoenfeld Y. Mixed connective tissue disease: an overview of clinical manifestations, diagnosis and treatment. Best Prac Res Clin Rheumatol 2012; 26: 61-72.

5. Zimmermann-Górska I. Mieszana choroba układowa tkanki łącznej i zespoły nakładania. In: Złota Seria Interny Polskiej. Reumatologia kliniczna [Polish]. Zimmermann-Górska I (ed.). Wydawnictwo Lekarskie PZWL, Warsaw 2009; 695-700.

6. Sierakowski S, Sierakowska M. Choroby twardzinopodobne. In: Złota Seria Interny Polskiej. Reumatologia kliniczna [Polish]. Zimmermann-Górska I. Wydawnictwo Lekarskie PZWL, Warsaw 2009: 624-38.

7. Zulian F, Vallongo C, Woo P, et al. Localized scleroderma in childhood is not just a skin disease. Arthritis Rheum 2005; 52: 2873-81.

8. Fett N, Werth VP. Update on morphea. Part I. Epidemiology, clinical presentation, and pathogenesis. J Am Acad Dermatol 2011; 64: 217-28.

9. Fett N, Werth VP. Update on morphea. Part II. Outcome measures and treatment. J Am Acad Dermatol 2011; 64: 231-42.

10. Kowal-Bielecka O, Bielecki M. Twardzina układowa. In: Wielka Interna. Reumatologia [Polish]. Puszczewicz M (ed.). Medical Tribune, Warsaw 2010; 127-41.

11. Kowal-Bielecka O, Kuryliszyn-Moskal A. Twardzina układowa. Reumatologia 2012; 50: 124-9.

12. Sierakowski S, Sierakowska M. Twardzina układowa. In: Złota Seria Interny Polskiej. Reumatologia kliniczna [Polish]. Zimmermann-Górska I (ed.). Wydawnictwo Lekarskie PZWL, Warsaw 2009; 2: 603-23.

13. Vancheeswaran R, Black CM, David J, et al. Childhood - onset scleroderma. Is it different from adult - onset disease? Arthritis Rheum 1996; 39: 1041-9.

14. Golding DN. Morphoea (localised scleroderma) in a patient with mixed connective tissue disease. Ann Rheum Dis 1986; 45: 523-5.

15. Rummler S, Althaus K, Maak B, Barz D. A case report of successful treatment with immunoadsorption onto protein $A$ in mixed connective tissue disease in childhood. Ther Apher Dial 2008; 12: 337-42.

16. Palmer GM, Sundel R, Berde CB, Sethna NF. Prolonged sensory and motor deficit following short-term lumbar epidural analgesia in a patient with mixed connective tissue disease. J Pain Symptom Manage 2002; 23: 89-92.

17. Bonin CC, Santos Pires da Silva B, Mota LM, de Carvalho JF. Severe and refractory myositis in mixed connective disease: a description of a rare case. Lupus 2010; 19: 1659-61.

18. Essalah AA, Eddy AA. A morbid course in a girl with mixed connective disease. Pediat Nephrol 1999; 13: 54-6.

19. Rech J, Kallert S, Hueber AJ, et al. Combination of immunoadsorption and CD2O antibody therapy in a patient with mixed connective disease. Rheumatology 2006; 45: 490-1. 